\title{
Erratum to: How Accurate are Paleoecological Reconstructions of Early Paleontological and Archaeological Sites?
}

\author{
Manuel Domínguez-Rodrigo • Charles M. Musiba
}

Published online: 24 August 2010

(C) Springer Science+Business Media, LLC 2010

\section{Erratum to: Evol Biol \\ DOI 10.1007/s11692-010-9087-2}

Due to the fact that one of the authors was unreachable in the field during the production of the proof, several errors were undetected in this paper before it was published online. These are as follows:

1. The definition of habitat (on page 2) and ecosystem is incomplete. For habitat it currently reads; a place where a population of animals and plants live, as well as their surroundings, both living and non-living. This should read as follows: A portion of the biome, which shows distinctive faunal, vegetational, trophic and lithological properties. For ecosystem it currently reads; An ecosystem here is considered as part of ecology consisting of the environment, its living parts, and the non-living factors that affect it. It should read: An ecosystem here is considered as part of ecology within a defined pluviometric regime consisting of the environment (with its range of habitats), its living parts, and the non-living factors that affect it.

2. Page 4 of the current pdf, first column, first paragraph, line 12. It reads: in this case lacustrine and alluvial

The online version of the original article can be found under doi:10.1007/s11692-010-9087-2.

M. Domínguez-Rodrigo

Departamento de Prehistoria, Universidad Complutense,

28040 Madrid, Spain

C. M. Musiba $(\bowtie)$

Department of Anthropology, University of Colorado Denver,

1201 5th Avenue, Suite 270, Denver, CO 80217, USA

e-mail: Charles.Musiba@ucdenver.edu habitats). It should read: (most of the time, alluvial habitats).

3. Page 7 of current pdf. First column, 4th paragraph. Here, the reference to Figure 2 is incorrect as it refers to a figure that was removed during revisions. This figure 2 does not exist in this paper.

4. Table 1 caption should be modified to: Minimum number of individuals (MNI) according to taxa reported in the Rwenzori National park for the whole ecosystem, the alluvial portion of the ecosystem and the thaphocoenosis documented in the latter.

5. Table 2 caption should be modified to: Number of animals collected throughout the alluvial woodland habitats sampled areas 1-6 in the Tarangire Park by Lamprey (1964). The areas sampled are: Riverine grassland, Acacia tortilis woodland, Gall Acacia woodland, drainage line woodland, Acacia-Commiphora woodland, Acacia mellifera-Commiphora woodland.

6. Figure 2 caption. The first sentence should be expanded as follows: Hierarchical agglomerative cluster analyses of several African national parks representing wooded biomes and more open savanna landscapes compared to two Pliocene hominin localities in Ethiopia. Data on bovid tribe..... 